\title{
Jornalismo multiplataforma e (des) convergência em Portugal
}

\author{
Multiplatform journalism and (de) convergence in Portugal \\ Periodismo multiplataforma y (des) convergencia en Portugal
}

DOI: $10.1590 / 1809-5844201822$

\section{Telma Sueli Pinto Johnson ${ }^{1}$}

http://orcid.org/0000-0002-7561-9794

${ }^{1}$ (Universidade Federal de Juiz de Fora, Faculdade de Comunicação, Curso de Jornalismo. Juiz de Fora - MG, Brasil)

\section{Resumo}

Este artigo analisa dinâmicas interacionais entre jornalistas do centenário diário português Jornal de Notícias durante a cobertura multiplataforma da tragédia de Pedrógão Grande. Os incêndios florestais ocorridos no verão europeu de 2017, na região central de Portugal, ganharam atenção midiática internacional pelas mortes provocadas e extensão de áreas devastadas. Adota-se a perspectiva da convergência midiática, atravessada por movimentos de divergência, desconvergência e coexistência, para compreender como o Jornal de Notícias se adapta e consegue ser competitivo no ecossistema midiático contemporâneo. O estudo de caso revela a adoção de um complexo modelo de convergência, que coloca em articulação novos e velhos processos e práticas profissionais que vão além do discurso simplista e dominante da convergência jornalística.

Palavras-chave: Convergência. Desconvergência. Jornalismo multiplataforma. Interações. Portugal.

\begin{abstract}
This article analyzes interactional dynamics between journalists of the Portuguese centenary newspaper Jornal de Notícias during the multiplatform coverage of the Pedrógão Grande tragedy. The forest fires in the summer of 2017 in central Portugal gained international media attention for the deaths caused and the extent of devastated areas. The perspective of media convergence is adopted, crossed by movements of divergence, deconvergence and coexistence, to understand how Jornal de Notícias adapts itself and manages to be competitive in the contemporary media ecosystem. The case study reveals the adoption of a complex model of convergence, which articulates new and old professional practices and processes that go beyond the simplistic and dominant discourse of journalistic convergence.
\end{abstract}

Keywords: Convergence. Deconvergence. Multiplatform journalism. Interactions. Portugal.

\section{Resumen}

Este artículo analiza dinámicas interactivas entre periodistas del centenario diario portugués Jornal de Noticias durante la cobertura multiplataforma de la tragedia de Pedrógão Grande. Los incendios 
forestales ocurridos en el verano europeo de 2017, en la región central de Portugal, ganaron atención mediática internacional por las muertes provocadas y extensión de áreas devastadas. Se adopta la perspectiva de la convergencia mediática, atravesada por movimientos de divergência, desconvergencia y coexistencia, para comprender cómo el Jornal de Noticias se adapta y consigue ser competitivo en el ecosistema mediático contemporáneo. El estudio de caso revela la adopción de un complejo modelo de convergencia, que pone en articulación nuevos y viejos procesos y prácticas profesionales que van más allá del discurso simplista y dominante de la convergencia periodística.

Palabras clave: Convergencia. Desconvergencia. Periodismo multiplataforma. Interactividad. Portugal.

\section{Introdução}

A digitalização e a convergência têm provocado profundas alterações nos processos de produção e distribuição de notícias em organizações jornalísticas tradicionais. Este trabalho examina a convergência jornalística, sobretudo experiências de divergência, desconvergência como movimento de reversão de processos convergentes e coexistência entre culturas impressa e digital, em práticas e rotinas profissionais na redação do centenário diário português Jornal de Notícias (JN), da cidade do Porto, norte de Portugal.

Uma reflexão inicial que se coloca é como um título, publicado ininterruptamente desde 1888, consegue se manter relevante no ecossistema midiático contemporâneo caracterizado pela crise nos modelos de negócios (PICARD, 2011), ciclos de publicação digital policrônicos ${ }^{1}$ (SALAVERRÍA, 2017) e audiências fragmentadas (MADIANOU, 2009). No contexto socioeconômico do jornalismo português, que não difere de outros países, um total de 183 jornais encerraram suas atividades entre 1995 e 2015².

As estratégias editoriais do Jornal de Notícias (JN), particularmente processos e dinâmicas interacionais (BLUMER, 1969; MEAD, 1934) entre profissionais novos e veteranos que tornam a produção jornalística possível, são o foco deste estudo de caso. O planejamento do estágio empírico da investigação levou em consideração a posição de liderança que o jornal vem assumindo no ranking netScope de tráfego multiplataforma auditado pela empresa Marktest em parceria com o operador internacional Gemius ${ }^{3}$.

Em 2016, o JN chegou ao segundo lugar em visitas totais multiplataforma (PC, mobile e tablet), com 225,8 milhões de acessos únicos, ficando atrás apenas do Correio da Manhã ${ }^{4}$, com o qual também disputa mercado na categoria de diário generalista no país ${ }^{5}$ com circulação impressa nacional. O ranking de tráfego mensal multiplataforma de janeiro

\footnotetext{
1 Salaverría (2017, p.25) define a temporalidade dos meios digitais em três tipos: "1) los periódicos - aquellos que respetan un intervalo temporal fijo entre sus ediciones - 2) los de actualización continua - aquellos cuyo ciclo de publicación viene dictado por la existencia de nuevas informaciones o, en última instancia, por el ritmo de la actualidad informativa -, y 3) los policrónicos o multitemporales - aquellos que mezclan características de los dos anteriores".

2 Consulta realizada na Base de Dados Portugal Contemporâneo - Pordata (Disponível em: https://www.pordata.pt. Acesso em: 23 jun. 2017).

3 Os rankings são publicados anualmente, desde 2014, com base na ferramenta de web-analytics gemiusPrism, utilizada em 30 países europeus.

4 O Correio da Manhã foi fundado em 1979 e é conhecido como um diário popular.

5 Os outros dois jornais são o Diário de Notícias e Público, da cidade de Lisboa.
} 
de $2017^{6}$ mostra que o domínio “jn.pt”, pela primeira vez, chegou ao topo entre os jornais de informação geral no país, com 23.366 milhões de visitas únicas, 72,2\% originadas de dispositivos móveis e 22,2\% de computadores pessoais.

O estágio de coleta de dados da pesquisa ocorreu em dois momentos sucessivos. Em um primeiro momento, entre 4 e 18 de junho de 2017, empregou-se técnicas de observação, monitoramento e construção de um banco de dados com o armazenamento de produtos digitais do JN, tais como edições do jornal impresso em formato PDF, capturas de telas das homepages do website e da Web móvel (domínio “jn.pt” e aplicativo JN para sistema operacional Android), newsletters e alertas automáticos de notícias de última hora.

Com base nos dados preliminares, um modelo de visitas técnicas ao JN para o segundo estágio de coleta de dados foi desenhado. O modelo articulou procedimentos de observação direta e entrevistas semiestruturadas, no esforço de apreender como a redação se organiza em suas atividades cotidianas e interacionais (PRUS, 1996) - e como os profissionais se percebem, no fazer jornalístico de produtos multiplataforma ${ }^{7}$. As visitas técnicas, previamente agendadas, foram realizadas no período de 19 a 22 de junho de 2017.

O trabalho de campo coincidiu com a onda de incêndios na vila de Pedrógão Grande, no distrito de Leiria, região central de Portugal. Os incêndios acontecem todos os anos, durante o verão europeu e há muito não eram considerados como "acontecimentos”, no sentido de eventos inesperados que perturbam a ordem social e o horizonte de expectativas (QUÉRÉ, 1997). Em 2017, contudo, os incêndios ganharam a dimensão de tragédia abrindo um debate público sobre causas e responsabilidades pela morte de 64 pessoas e a devastação de uma área total de 52.992 hectares.

Assim, este artigo examina o trabalho jornalístico na redação do JN, seus pontos de fuga e interseção com práticas do passado, num momento fortemente influenciado pelos acontecimentos de Pedrógão Grande, área de proximidade geográfica do JN.

\section{De qual convergência estamos falando?}

O conceito de convergência, substantivo feminino derivado do latim convergentia (união), tornou-se tão polissêmico quanto evasivo no campo de estudos da Comunicação. Sob o guarda-chuva da convergência têm-se abrigado tantos fenômenos que a relação entre objetos científicos e sua aliança representativa conceitual (FERRARA, 2010) pode ser colocada sob suspeita.

O problema reside, em linhas gerais, na carga de abstração do termo como ferramenta analítica capaz de explicar elementos distintivos do complexo processo de transformação

6 Fonte: Ranking netScope de janeiro de 2017. Disponível em: http://net.marktest.pt/netscope/rankings-netscope/ranking-netscope-de-janeiro-de-2017/. Acesso: 15 maio 2017.

7 Veglis (2016) define multiplataforma como a produção de qualquer conteúdo (notícias, música, texto, imagens, etc.) para mais do que uma plataforma (impresso, web e TV) dentro da mesma organização midiática. 
no cenário comunicacional, nas sociedades contemporâneas, de outros fenômenos que estão acontecendo como reação, e em paralelo, à convergência midiática.

Num estudo sobre a história cultural do termo convergência midiática na literatura científica, Balbi (2017) identificou quatro narrativas inter-relacionadas, com diferentes significados que se sobrepuseram durante décadas recentes, provocando a confusão do conceito.

A convergência tecnológica foi a primeira a aparecer e dominou o discurso geral pelo menos desde os anos 1980. A convergência econômica/mercadológica tornou-se relevante devido às integrações entre indústrias midiáticas diferentes e alcançou seu pico durante os anos 1990. Consequentemente, políticos começaram a pensar sobre novas formas de regular os ambientes convergentes durante a segunda metade de 1990 nos Estados Unidos e Europa. Finalmente, começando dos anos 2000, o fenômeno da convergência cultural pareceu ser uma das tendências mais relevantes da mídia contemporânea (BALBI, 2017, p.46).

$\mathrm{Na}$ tentativa de reduzir ambiguidades, pesquisadores têm sugerido dissociar o conceito abstrato da definição operacional de convergência, levando em consideração contextos geoeconômicos e culturais específicos. Arango-Forero, Roncallo-Dow e Uribe-Jongbloed (2016) propõem, por exemplo, a adoção combinada da perspectiva da reprodutibilidade técnica benjaminiana com a perspectiva sensorial mcluhaniana para conceber a convergência ${ }^{8}$ como processo comunicativo tangível de ser estudado.

Na visão de Arango-Ferrero et al (2016, p.24), “Convergência não é um processo que pode ser mostrado somente pelo uso de aplicações tecnológicas, mas que tem lugar, até certo ponto, nas mentes dos consumidores como indivíduos [...] e através de suas interações sociais”. Na mesma linha, Lugmayr e Dal Zotto (2016) defendem a convergência como processo contínuo ${ }^{9}$, mas argumentam que o contexto midiático industrial exige uma discussão mais ampla sobre a evolução da mídia e seus princípios.

Lugmayr e Dal Zotto (2016) acreditam que um bom ponto de partida para entender os desenvolvimentos na indústria midiática é associar a ideia de evolução biológica ${ }^{10}$ ao mundo da mídia, particularmente aos fenômenos de convergência, divergência e coexistência. Com base num mapeamento quanti-qualitativo de publicações do ano de 2015 no campo de pesquisa da convergência midiática, eles constataram a predominância de abordagens unilaterais sobre convergência, com escassas contribuições sobre suas interações com processos de divergência e coexistência.

8 Os autores se referem à relacionalidade entre o humano e a técnica como condição constitutiva da realidade social.

9 Jenkins (2009) tratou da "falácia da caixa-preta" para desmistificar discursos reducionistas sobre o surgimento de um meio de comunicação único, baseado em tecnologias digitais convergentes em formatos e padrões, que negligenciam aspectos culturais.

10 Os autores trabalham com duas teorias da evolução biológica como processo: a teoria da convergência, que explica estados presentes de uma espécie como determinado por precondições naturais existentes, e a teoria da contingência, que acentua estados presentes como emergências acidentais não-replicáveis apesar das mesmas condições preexistentes. 
Em face desses achados, Lugmayr e Dal Zotto (2016, p.431) reivindicam que “adaptação, especialização, coevolução e extinção da mídia são fenômenos resultantes não somente da convergência midiática, mas, também, de processos de divergência e coexistência”. Os autores citam, como exemplo, que a noção de adaptação pode ser comparada aos desenvolvimentos tecnológicos que os jornais tradicionais têm enfrentado na transição entre versões impressas para publicações online, permitindo modelos de assinaturas online e micropagamentos.

Ainda na esfera do jornalismo, Lugmayr e Dal Zotto (2016) observam que a especialização está no cerne da história do desenvolvimento dos meios de comunicação de massa com a fragmentação de nichos de audiência. A cooperação é identificada por atividades de fusão e aquisição entre empresas que competem num ambiente midiático mutável ou que querem ganhar conhecimento e adquirir sucesso no domínio digital. Extinção, nessa perspectiva, tem como exemplos inúmeras empresas que fecharam pela incapacidade de adaptação ao novo ambiente digital.

No âmbito do nosso objeto de estudo, as relações entre convergência, divergência e coexistência são relevantes porque permitem compreender conexões, interseções, inclusões e exclusões que se processam na dinâmica de produção e distribuição dos produtos multiplataforma do Jornal de Notícias.

Nos dados que emergiram na primeira fase da coleta de dados, nota-se um triplo movimento editorial de divergência de gêneros, linguagens e formatos, a partir de conteúdos convergentes, que não seguem a lógica de produção linear do produto impresso. Ainda assim, as versões impressa (publicada também em formato PDF) e digital do JN coexistem na estrutura organizacional da empresa.

Por outro lado, simultaneamente, a convergência tecnológica é evidente nos conteúdos jornalísticos multimídia (textos, vídeos, áudios, infográficos) disponibilizados pelo jornal, em alguns casos em tempo real, para suas plataformas digitais. Um produto, em especial, merece ser citado. É o widget de web TV “JN Direto”, que aparece nas interfaces para dispositivos fixos e móveis como um botão virtual. O JN Direto apresenta uma síntese das principais notícias do dia em 60 segundos e é atualizado, em média, 20 vezes por dia. Se considerarmos que o JN Direto é uma unidade audiovisual adicional encaixada nos canais digitais do JN, então temos, novamente, um processo de diversificação e, portanto, divergência.

As fronteiras entre processos de convergência, divergência e coexistência midiática são fluidas, daí porque é preciso dar um passo adiante para compreender o funcionamento e a lógica dos objetos do mundo empírico. Há uma década, Fagerjord e Storsul (2007) já questionavam o discurso dominante da relação direta entre digitalização e convergência, chamando a atenção para o uso da metáfora convergência como "simplificação da complexidade” (p.28) da mídia e da mudança tecnológica. 
Um aspecto dessa simplificação é como a convergência tem sido usada para descrever mudanças em práticas sociais. Na indústria jornalística, Fagerjord e Storsul (2007) observaram que a introdução das tecnologias digitais foi usada para juntar partes de organizações e sistemas que tinham funções separadas. "Tipicamente, as técnicas de produção digital têm feito as instituições de mídia se reorganizar e unir jornalistas dentro da mesma área jornalística (notícias, entretenimento, esportes etc.), não importando se eles produzem para TV, rádio ou web” (p.29).

Em face à complexidade das mudanças tecnológicas e suas imbricações sociais, concordamos com Peil e Sparviero (2017) que os desenvolvimentos recentes precisam ser estudados como interação de processos de convergência e desconvergência midiáticas. O termo “desconvergência” (deconvergence) é utilizado por Jin (2011) para descrever a tendência de queda da convergência e a emergência da desconvergência em indústrias globais de comunicação. O movimento de reverter alianças e fusões, realizadas nos anos de 1990, é identificado como novo modelo de negócios do século XXI. Neste sentido, desconvergência é um desdobramento da convergência, que tem como causa principal negócios que se uniram e não deram certo.

Na perspectiva de Peil e Sparviero (2017), adotamos neste trabalho uma noção mais ampla de desconvergência para explorar a existência ou não de processos e/ou movimentos de reversão que acompanham a convergência midiática, do ponto de vista da organização social das atividades jornalísticas, na redação multiplataforma do Jornal de Notícias, que traz, em sua longa trajetória, a cultura do impresso. Como Peil e Sparviero (2017) observam,

Desconvergência também representa a negação em reconhecer mudanças contínuas como lineares, processos conectados, levando a soluções previsíveis. A perspectiva sobre desconvergência [...] pode ajudar a clarear a natureza ambivalente da convergência midiática e a simultaneidade de relações de força tais como associação e separação, ou linearidade e descontinuidade (p.7).

O planejamento da segunda etapa de coleta de dados desta investigação flexibilizou o conceito de convergência em redações jornalísticas, considerando questões relativas às divergências e conflitos relatados na literatura do campo (ERDAL, 2007; AVILÉS et al, 2009; GORDON, 2003; MITCHELSTEIN; BOCZKOWSKI, 2009; QUANDT; SINGER, 2009; SPYRIDOU; VEGLIS, 2016), para abrigar a desconvergência jornalística como possibilidade teórico-metodológica.

Aqui, desconvergência jornalística é tomada como conceito sensibilizante (BLUMER, 1954), na tentativa de deslocar o olhar de modelos preconcebidos, com seus atributos e referências, para desvelar outras instâncias empíricas não cobertas pelo conceito. Em função da escassez de produção científica sobre convergência em redações portuguesas 
tradicionais, que tratem especificamente de práticas e rotinas editoriais, tomamos como referência estudos quantitativos recentes que comparam estágios de convergência jornalística em redações europeias (MENKE et al, 2016) ${ }^{11}$.

Os achados de Menke e seus colegas (2016) mostram que processos de convergência estão acontecendo mais rápido em países mediterrâneos, como Espanha e Portugal, do que em países da Europa Central/Norte. Os motivos, segundo os autores, estão relacionados à maior ou menor tradição jornalística impressa e audiovisual. No estudo, Portugal desponta na primeira posição como país mais adaptável à cultura da convergência jornalística.

\section{Fazendo sentido do JN no século XXI}

O trabalho de campo na redação do Jornal de Notícias foi realizado no período de 19 a 22 de junho de 2017, com a adoção de técnicas de coleta de dados simultâneas que são tratadas, nesta etapa, como unidades analíticas distintas para facilitar a compreensão da experiência e do vivido no processo de convergência profissional do jornal.

A primeira operação teórico-metodológica utilizou um modelo de observação direta focado na organização espacial e temporal do ambiente, para compreender como o trabalho jornalístico é realizado e como as características físicas facilitam ou restringem interações sociais na redação. Na segunda operação, empregou-se um modelo de entrevistas individuais semiestruturadas gravadas com jornalistas responsáveis pelos conteúdos multiplataforma e impresso do jornal, bem como conversas com repórteres sobre rotinas profissionais.

O desenho inicial de ambos os construtos de coleta de dados, durante a fase de desenvolvimento empírico, foi adaptado ao contexto dos eventos imprevistos que aconteceram às vésperas das visitas técnicas à sede da redação do JN - a sucessão de incêndios florestais iniciados na vila de Pedrógão Grande, que depois se espalharam para outros municípios vizinhos, na região central de Portugal. Os incêndios são comuns no país, em função do clima mediterrâneo que permite o crescimento da vegetação tanto no inverno como no verão, mas ganharam força de tragédia com a morte de 64 pessoas, 250 feridos e uma área devastada de 52.992 hectares.

Os incêndios em Pedrógão Grande começaram na tarde do sábado, 17 de junho, mas somente no final da noite soube-se da dimensão dos acontecimentos. Apenas dois jornais impressos portugueses publicaram a notícia como manchete em suas capas no dia seguinte o Correio da Manhã, pertencente ao Grupo Cofina, e o Jornal de Notícias, do Global Media Group. Correio e JN competem na circulação impressa e multiplataforma em âmbito nacional.

Durante o domingo, dia 18, o JN atualizou seus leitores sobre o descontrole das chamas, balanços do número de vítimas e sobreviventes, mobilizações dos bombeiros

11 A survey, realizada entre 2014 e 2016, comparou estratégias de convergência jornalística em redações jornalísticas da Alemanha, Holanda, Suíça, Áustria, Espanha e Portugal. 
e equipes de resgate, relatos de testemunhas e reações das autoridades. As atualizações chegavam como notificações de breaking news, flashes diretos de repórteres em campo e atualização contínua das homepages do website e da Web móvel, além do aplicativo JN. As plataformas digitais mantiveram um fundo de cor vermelho intenso, como sinal de alerta sob o selo "Fogos".

Figura 1 - Capturas de telas da Web móvel do JN do dia 18 de junho de 2017

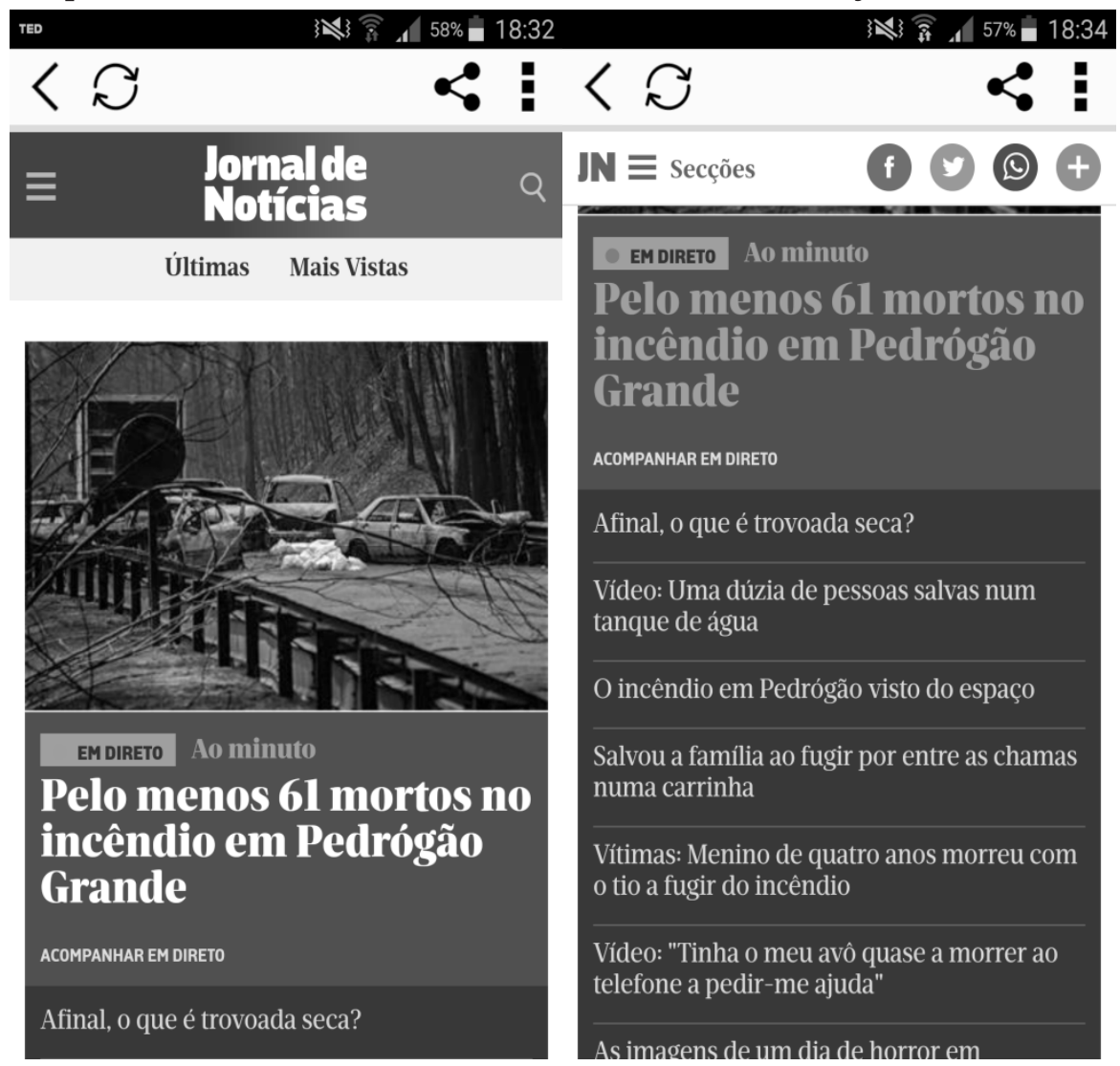

Fonte: Autoria própria.

No primeiro dia de visita ao JN, segunda-feira 19 de junho, a edição impressa do jornal chegou às bancas com as tradicionais 56 páginas em formato tabloide, estampando como manchete de capa a pergunta "Como foi possível?”, seguida de subtítulos como “Inferno”, “Reportagem”, “Causas”, “Meios” e "Floresta”, com pequenas unidades de chamada que remetiam para a extensão da cobertura jornalística da tragédia nas páginas internas.

O plano de fundo da capa foi todo coberto por uma foto do $\mathrm{Km} 7$ da estrada nacional (EN) 236, epicentro dos acontecimentos em Pedrógão Grande, onde morreram 47 pessoas, 
30 carbonizadas no interior de carros e outras 17 que tentavam fugir dos veículos. A edição dedicou 26 das suas 49 páginas de conteúdo informativo (sete páginas foram de anúncios publicitários), isto é 53\%, para a cobertura que movimentou profissionais de quase todas as editorias do jornal em pleno dia de domingo.

Figura 2 - Edição impressa do JN do dia 19 de junho de 2017

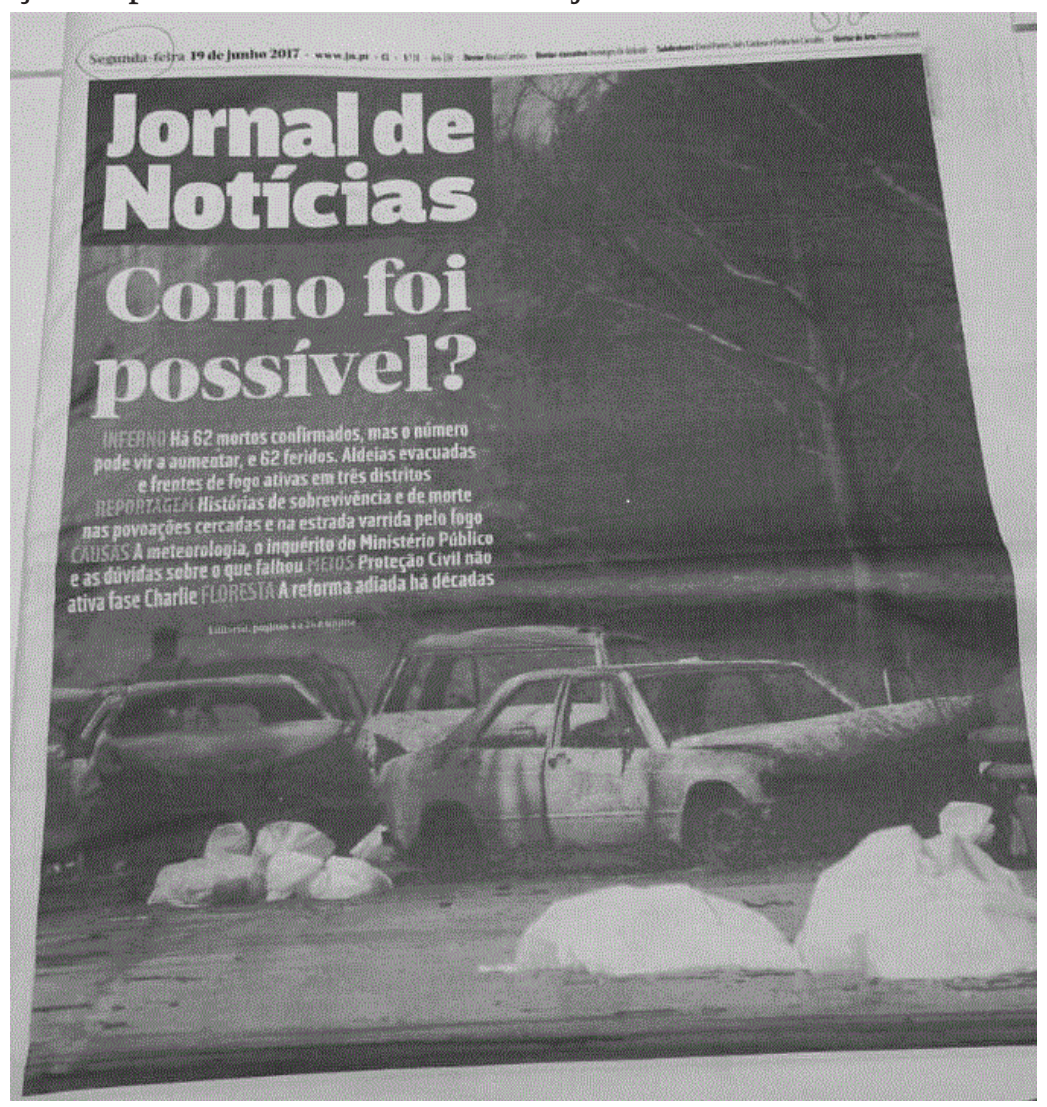

Fonte: Autoria própria.

O tom crítico e a angulação da cobertura nas versões impressa e digitais do jornal foram demonstrados no editorial intitulado "Caminho do inferno":

A origem da ignição está identificada e fenômenos naturais extremos criaram condições para que o fogo alastrasse com uma violência rara e que ninguém conseguiria suster. Mas na evolução do fogo concorreram muitos fatores. Seja as estratégias de combate ou as condições de vegetação. As condições naturais não explicam tudo. E quem conhece o estado em que está aquela que já foi orgulhosamente classificada como a maior mancha contínua de pinheiro-bravo da Europa não pode fingir que não vê o risco (JORNAL DE NOTÍCIAS, 2017, p.2). 
No mesmo editorial, o JN questiona causas, responsabilidades e indecisões sobre a defesa da floresta e das populações que as habitam:

A dispersão da propriedade, a cada vez menor produtividade da floresta, a total ausência de investimento, tudo contribui para um abandono perigoso. E, lá está mais uma vez o nosso desequilíbrio, uma larga faixa do país despovoado que corta raízes com a ruralidade. A floresta é cada vez menos rentável. Sendo cada vez menos rentável, cada vez se cuida menos dela. Está instalado o ciclo vicioso (JORNAL DE NOTÍCIAS, 2017, p.2).

\section{Organização espacial e temporal do ambiente de trabalho}

Dois artefatos representativos da cultura organizacional chamam a atenção no corredor que leva à redação do JN. Afixada numa parede de alto a baixo, está uma reprodução gigante da capa da primeira edição impressa do jornal, datada de 2 de junho de 1888 (Figura 3), que traz entre os destaques sob o título "Compromisso de confiança” os princípios da política editorial do veículo. Do outro lado do corredor, fica em exposição uma máquina de linotipia (Figura 3) que fora utilizada nos processos de composição mecânica no final do século XIX.

Figura 3 - Artefatos da memória organizacional do Jornal de Notícias

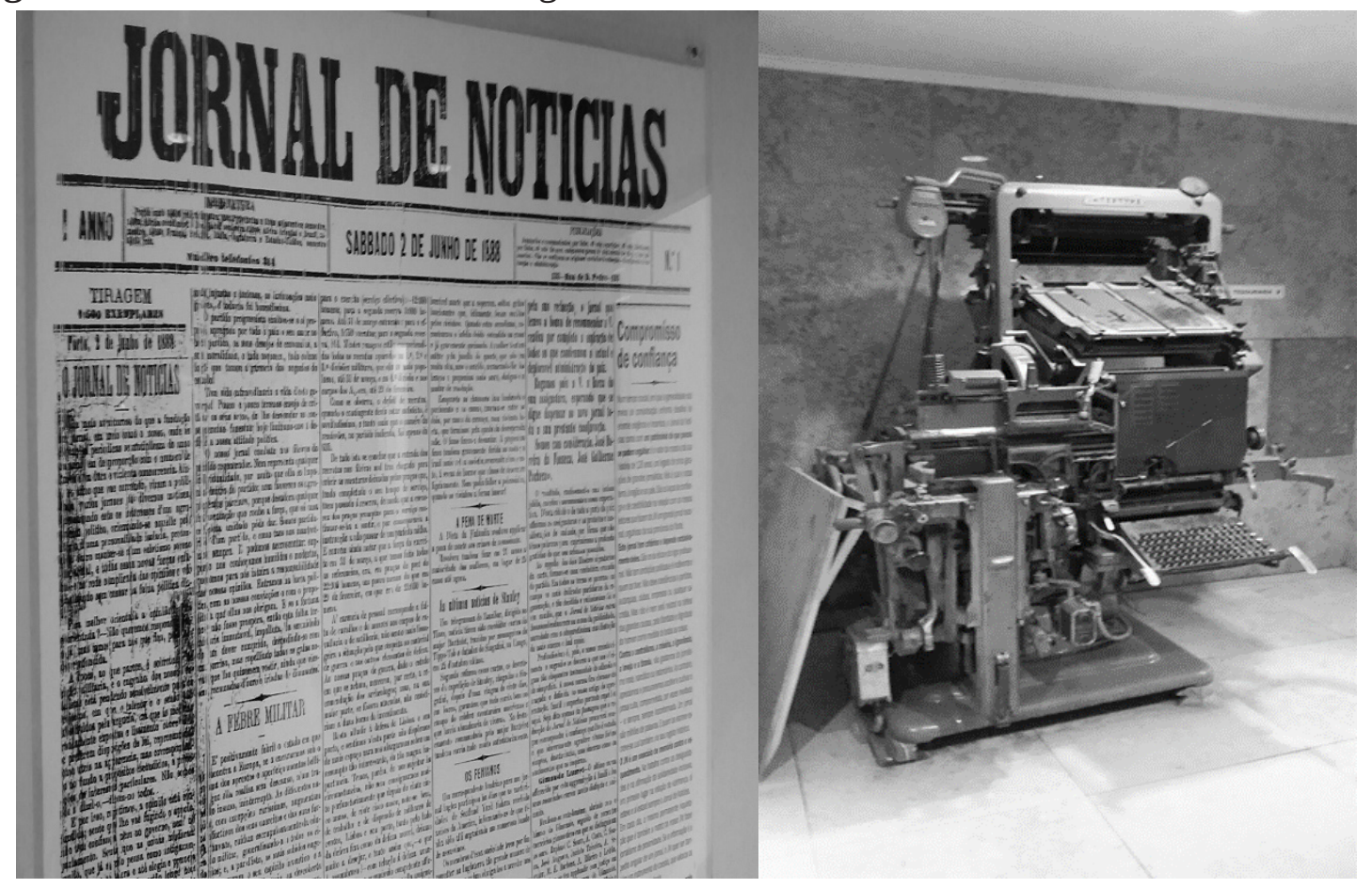

Fonte: Autoria própria. 
Na redação, o layout físico tem um longo formato retangular que lembra características de uma redação jornalística tradicional, embora não haja baias divisórias entre postos de trabalho e nem entre seções editoriais. Há, contudo, elementos na configuração estrutural que estão dispostos de tal forma que são percebidos, de imediato, como contrastantes com o restante da organização espacial.

No centro da redação funciona uma grande estação de trabalho aberta, composta por mesas contíguas que formam um núcleo circular, equipada com computadores e telas de diversos tamanhos. No teto, como uma espécie de guarda-chuva sobre a estação, estão 12 monitores de televisão ligados a canais noticiosos. Esta é a célula digital do jornal (Ilustração 1), onde trabalha o editor-executivo adjunto com profissionais do jornalismo multiplataforma, entre eles o editor de redes sociais. O layout desse espaço de trabalho representa áreas em que o tempo é fator-chave e imprime o ritmo na produção e distribuição de notícias.

No entorno retangular da célula digital, com monitores de televisão por todos os lados, estão distribuídos postos de trabalho e editorias de Nacional, Local (Porto), Justiça, Etc. (Artes e entretenimento), Desporto, Mundo e Maquetagem. Ao todo, são 55 jornalistas na sede da redação e outros 23 profissionais que trabalham na área de suporte. O jornal também mantém 50 colaboradores permanentes ao redor do país, entre eles 18 jornalistas correspondentes na capital Lisboa.

Ilustração 1 - Organização espacial e temporal simplificada da redação do JN (*)

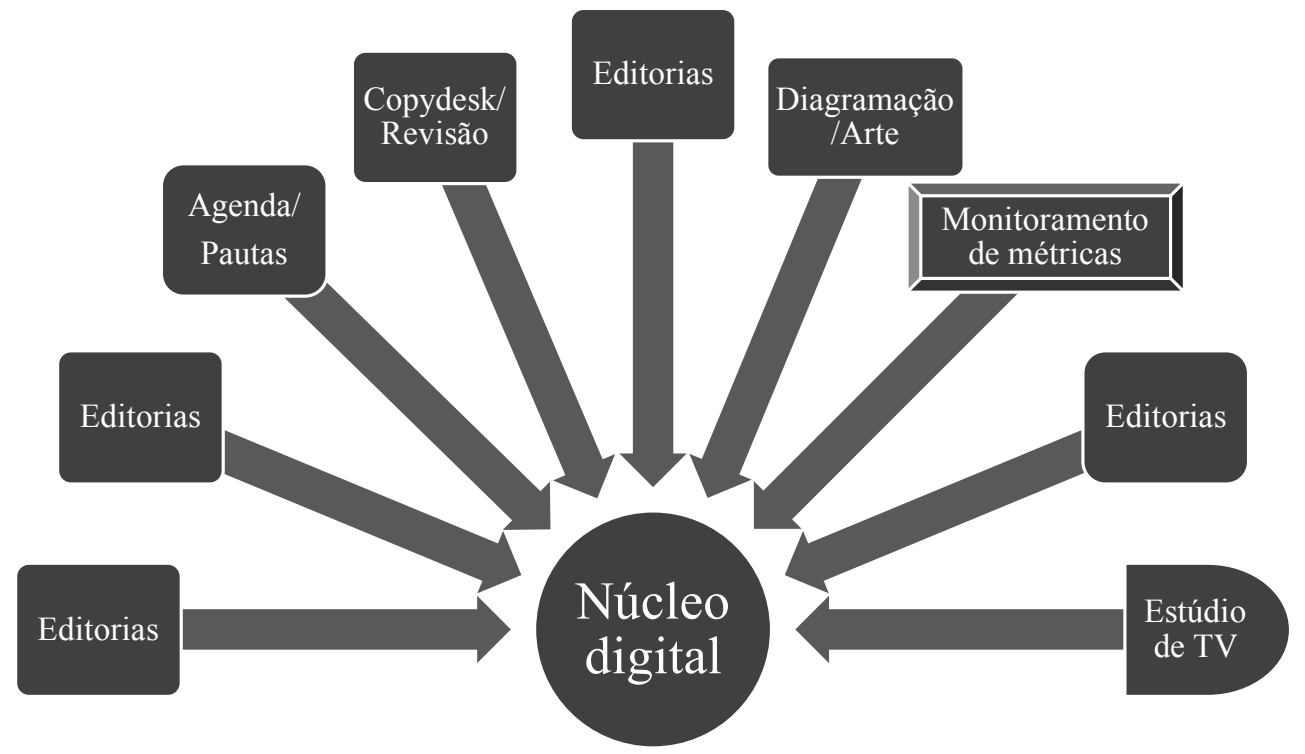

Fonte: elaboração própria.

(*) O diagrama não inclui salas de reunião, da direção de jornalismo, da secretaria de redação, de arquivos de jornais impressos e áreas livres conjugadas à redação, mas que ficam separadas por divisórias e vidros. 
Outro elemento destoante na organização física do trabalho, tomando como base de comparação o layout de redações impressas tradicionais, é o amplo espaço adjacente à redação onde está localizado o estúdio de TV do jornal. O estúdio é utilizado para a produção e transmissão de audiovisuais informativos e de entretenimento, muitas vezes em tempo real, como a apresentação de bandas musicais e flashes de repórteres para plataformas digitais do JN, incluindo suas páginas em redes sociais. É neste estúdio que são produzidas as edições diárias do widget de TV JN Direto, mencionado anteriormente.

Um terceiro elemento inovador é o funcionamento de um grande painel de controle da ferramenta norte-americana Chartbeat Publishing, que pode ser visualizado e consultado de qualquer ângulo da redação. O software exibe métricas e análises, a cada segundo, sobre o comportamento de usuários ativos usando os produtos digitais do JN, com dados segmentados por tipos de dispositivos acessados (PC, mobile e tablet), origem do tráfego (homepages do JN, links, redes sociais ou instrumentos de busca) e atividades de engajamento com o conteúdo (tempo que os usuários gastam lendo, assistindo vídeos ou comentando).

O Chartbeat é constantemente utilizado, principalmente pelo "núcleo digital" que, como demonstra a Ilustração 1, é responsável pela absorção, filtragem, coordenação e gerenciamento de todo o fluxo de trabalho diário na redação do JN. O núcleo digital é a unidade para onde converge toda a produção jornalística, funciona como mediador permanente nas relações entre os profissionais de diferentes editorias ${ }^{12}$ e faz a ponte com produtores, correspondentes e repórteres em campo. É também este núcleo que define as breaking news, o que é prioridade para as versões digitais e o que pode ser diferencial para a versão impressa do dia seguinte.

Notou-se que o monitoramento do Chartbeat guia, ao longo do dia, decisões editoriais rápidas em função do recurso Top Pages, que mostra as notícias mais lidas nos websites do JN, comparando com as atividades do número total de usuários em dado momento. Esse acompanhamento auxilia na tomada de decisões sobre quais assuntos merecem maior ou menor investimento da equipe como, por exemplo, se vale a pena incluir fotografias para aumentar o número de page views. A ferramenta funciona agregada ao sistema de gerenciamento de conteúdo in-house do JN, o Millenium.

As decisões editoriais também consideram formas de acesso por tipo de dispositivo e browsers de acordo com os horários do dia. Uma leitura dos números do Chartbeat às 17h08 do dia 19 de junho, por exemplo, mostrava que 7.996 usuários estavam nas plataformas digitais do JN (84\% nos sites e 16\% no Facebook), sendo que 50\% via desktop, $46 \%$ via smartphones e 4\% via tablets. No dia 20, às 16h19, eram 6.500 usuários, 57\% em desktops, 39\% em smartphones e 4\% em tablets. O alto acesso móvel, em todos os horários do dia, é utilizado como estratégia pelo JN para a publicação de vídeos digitais sempre

12 Outras formas de interação entre os profissionais são as reuniões de planejamento semanais, às quartas-feiras, e as reuniões diárias que sempre acontecem às $10 \mathrm{~h}$. 
com legendas de texto, permitindo que os usuários dispensem o uso do áudio em seus movimentos migratórios em casa, na rua, na escola ou no trabalho.

\section{Desafios e avanços da convergência profissional no JN}

Os registros e observações do ambiente de trabalho sugerem traços evidentes de convergência nos processos de produção jornalística na redação do JN. É perceptível, pelo desenho da redação e fluxos de trabalho, que o núcleo digital é responsável não apenas pelo planejamento e ritmo de produção e distribuição multiplataforma, mas também exerce influência direta no produto impresso.

A complexidade da questão sobre como tornar um jornal centenário relevante, na segunda década do século XXI, é endereçada agora com trechos extraídos de entrevistas gravadas sobre meandros, limites, desafios e possibilidades da convergência. Uma das questões tratadas com o jornalista Manuel Molinos, editor-executivo adjunto do JN e coordenador do núcleo digital, foi como o jornal lida com o desafio de diferenciar seus produtos no digital e no papel.

Molinos foi um dos primeiros jornalistas a ter formação acadêmica em Comunicação Social em Portugal, em 1989, e desde 1999 trabalha na área digital do JN. Ele admite que as decisões editoriais entre o que é prioridade no digital e o que é prioridade no papel são uma das principais controvérsias no dia a dia da redação.

É uma das tarefas mais complexas e, digamos, a mais polêmica. Certamente erramos, às vezes acertamos, mas fazemos essa gestão - continuar a decidir em que determinada altura e em que determinado momento temos uma matéria que é exclusivamente nossa e vamos tentar que ela seja mais uma mais-valia na edição impressa. Em outras, achamos que essa matéria pode ser trabalhada de uma forma no digital e outra na impressa e avançamos assim. Portanto, é uma discussão que se faz diariamente e a toda hora. (Entrevista com Manuel Molinos).

O jornalista explica que embora a redação seja integrada, em termos espaciais e de fluxos de conteúdos que migram para o digital e vice-versa, há uma separação, na prática, na organização social das atividades. Há os jornalistas nitidamente da cultura do impresso e jornalistas que garantem os breaking news, o Última Hora, os compartimentos específicos do site - conteúdos multimídia feitos em HTML5, de vídeo, de infografia e os que precisam de programação ${ }^{13}$. Isso acontece, segundo Molinos, pela natureza específica do jornalismo digital. Como ele observa:

13 A equipe de jornalistas digitais trabalha por escalas, em turnos que começam às 7 h30 e se estendem até 
Um jornalista no digital tem que estar muito focado no digital, tem que ser muito rápido, tem que ser muito certeiro. No jornalismo digital, o perfil do jornalista não é igual para todos - no sentido notícia, de chegar primeiro e chegar da melhor forma possível - o que é muito complicado chegar primeiro e chegar bem. Essa procura da informação é sistemática, essa atenção em validar a informação, tudo de forma muito rápida e, portanto, nosso período de reflexão é muito pequeno. (Entrevista com Manuel Molinos).

A estratégia de convergência do jornal é fazer uma transição de integração no mesmo suporte de acordo com o tempo e à medida que novos profissionais chegam ao mercado, para evitar mudanças dramáticas. No cenário atual do jornalismo português, Molinos considera que “a integração total das redações é mais uma teoria acadêmica” do que uma prática.

Estamos na fase das convergências, das integrações, mas como estou aqui há muitos anos tenho uma opinião diferente e mais ampla sobre o assunto [...] É muito complicado trazer um jornalista que esteja no seu suporte impresso rapidamente para um ambiente desse. E depois, também, porque temos aqui a questão da especialização. Embora no digital haja a especialização na linguagem, na narrativa, na forma das hiperligações, na forma visual - que é muito específica, por outro lado não é especializado quase em nenhum assunto. Isto é, um jornalista na área digital tem que responder rapidamente ao assunto que se quer, seja desporto, mundo, política internacional, política geral, acidente, incêndio, atentado, portanto [risos] “ziliões” de especializações. (Entrevista com Manuel Molinos).

Essa distância entre gerações de jornalistas profissionais, cada qual com seus limites e possibilidades, é um dos principais desafios na experiência de convergência na redação do JN. Um exemplo é o caso do editor de redes sociais do jornal, formado numa universidade portuguesa com doutoramento numa universidade do Texas, que não faz marketing digital, mas seria como se fizesse porque precisa ter noção de outros elementos que não são propriamente jornalísticos, como falar com usuários, responder mensagens, olhar para as estatísticas do Chartbeat, avaliar o que o jornal está fazendo bem, fazendo mal, enfim manter as comunidades ativas.

Nesse processo, o jornal precisa levar em consideração que o maior negócio da empresa ainda é a publicidade e venda no papel. Em 2016, a receita do JN foi de oito milhões de euros, mas só 14\% foram negócios resultantes de operações digitais.

\section{Considerações finais}

Uma das principais conclusões a que chegamos nesta investigação é que o centenário diário português Jornal de Notícias consegue se manter competitivo no ecossistema midiático 
contemporâneo pela adoção de um complexo modelo de convergência, que coloca em articulação novos e velhos processos e práticas profissionais que foge do discurso simplista e dominante de convergência midiática.

Na organização das atividades cotidianas na redação, há marcas de convergência de conteúdos jornalísticos que migram entre os produtos digitais e impresso, ganhando linguagens, formatos e temporalidades específicas que são, ao mesmo tempo, divergentes e coexistentes. Por outro lado - em função da própria estratégia do jornal de conciliar a cultura do impresso com a cultura digital, emergem tensões, dilemas e forças em disputa nas interações sociais entre jornalistas novos e veteranos, bem como nos processos de decisão editorial.

Essas experiências são percebidas como alertas diários e contínuos acionados pelas complexas relações entre jornalismo e tecnologia que podem ser melhor compreendidas sob a perspectiva da desconvergência. Embora jornalistas novos e veteranos dividam o mesmo espaço físico e sejam todos diretamente influenciados pelo fluxo e escolhas editoriais do núcleo digital, há uma diferença, na prática, entre os perfis profissionais dos jornalistas que trabalham diretamente com os produtos digitais - garantindo as breaking news, atualizações do website, redes sociais e produção de conteúdos multimídia - e os experientes jornalistas do impresso com suas habilidades para análise, interpretação e contextualização das notícias.

Nossos achados sugerem que a decisão estratégica do jornal de recuar para um modelo de convergência mais lento e menos traumático está no reconhecimento de que, enquanto as versões impressa e digital coexistirem na estrutura organizacional da empresa, os diferentes perfis profissionais se complementam em competências e atributos. Um pelo lado da especialização técnica, o outro pela especialização editorial. Nesse processo (des) convergente, a redação funciona porque o núcleo digital atua como pivô na mediação das interações que tornam a produção jornalística possível.

Este trabalho teve o propósito de contribuir para a reflexão sobre o fenômeno da convergência midiática dentro de uma perspectiva mais ampla que abriga processos paralelos de divergência, coexistência e desconvergência ainda pouco estudados empiricamente no campo de estudos do Jornalismo. É um ponto de partida para compreender o que vem acontecendo com experiências de convergência e seus desdobramentos como movimentos que deslocam a centralidade da convergência como metáfora para contextos situacionais específicos do mundo real das redações jornalísticas.

\section{Referências}

ARANGO-FORERO, G.; RONCALLO-DOW, S.; URIBE-JONGBLOED, E. Rethinking convergence: A new word to describe an old idea. In: LUGMAYR, A.; DAL ZOTTO, C. Media convergence handbook - Vol. 1: Journalism, broadcasting and social media aspects of convergence. Berlin: Springer, 2016. p.17-28. 
AVILÉS, J. A. et al. Newsroom integration in Austria, Spain and Germany: models of media convergence. Journalism Practice, v.3, n.3, p.285-303, 2009.

BALBI, G. Deconstructing "Media Convergence": a cultural history of the buzzword, 1820s-2010s. In: SPARVIERO, S.; PEIL, C.; BALBI, G. Media convergence and deconvergence: global transformations in media and communication research. Cham, Switzerland: Springer, 2017. p.31-50.

BLUMER, H. What is wrong with social theory? American Sociological Review, v. XIX, p.3-10, 1954.

Symbolic Interactionism: perspective and method. New Jersey: Prentice-Hall, 1969.

ERDAL, I. J. Researching media convergence and crossmedia news production. Nordicom Review, v.28, n.2, p.51-61, 2007.

FAGERJORD, A.; STORSUL, T. Questioning convergence. In: STORSUL, T.; STUEDAHL, D. Ambivalence towards convergence: digitalization and media change. Göteborg: Nordicom, 2007. p.19-31.

FERRARA, L. D. A estratégia empírica da comunicação. In: BRAGA, J. L.; VASSALO DE LOPES, M.; MARTINO, L. C. Pesquisa empírica em comunicação. São Paulo: Paulus, 2010. p.51-69.

GORDON, R. The meanings and implications of convergence. In: KAWAMOTO, K. Digital journalism: merging media and the changing horizons of journalism. Oxford: Rowman \& Littledfield, 2003. p.57-72.

JENKINS, H. Cultura da convergência. São Paulo: Aleph, 2009.

JIN, D. Y. De-convergence and the deconsolidation in the global media industries: the rise and fall of (some) media conglomerates. In: WINSECK, D.; JIN, D. Y. Political economies of the media: the transformation of the global media. London, UK: Bloomsburry, 2011. p.167-182.

JORNAL DE NOTÍCIAS. Editorial Caminhos do Inferno, Porto, p.2, 19 junho 2017.

LUGMAYR, A.; DAL ZOTTO, C. Media convergence is NOT king: the triadic phenomenon of media “convergence-divergence-coexistence” IS king. In: LUGMAYR, A.; DAL ZOTTO, C. Media convergence handbook - Vol. 2, Firms and Users Perspectives. Berlin: Springer, 2016. p.429-455.

MADIANOU, M. Audience reception and news in every day life. In: WAHL-JORGENSEN, K.; HANITZSCH, T. The handbook of journalism studies. New York: Routledge, 2009. p.325-337.

MEAD, G. Mind, self, and society. Chicago: The University of Chicago Press, 1934.

MENKE, M. et al. Convergence culture in European newsrooms: comparing editorial strategies for crossmedia news production in six countries. Journalism Studies, 2016, v. 19, n.6. Disponivel em: http://dx.doi. org/10.1080/1461670X.2016.1232175. Acesso em: 11 out. 2016.

MITCHELSTEIN, E.; BOCZKOWSKI, P. Between tradition and change: a review of recent research on online news production. Journalism, v.10, n.5, p.562-586, 2009.

PEIL, C.; SPARVIERO, S. Media convergence meets deconvergence. In: BALBI, G.; SPARVIERO, S.; PEIL, C. Media convergence and deconvergence: global transformations in media and communication research. Cham, Switzerland: Springer, 2017. p.3-30.

PICARD, R. Digitization and media business models: mapping digital media. Open Society Institute, 2011. Disponivel em: https://www.opensocietyfoundation.org/sites/default/files/digitization-media-businessmodels-20110721.pdf. Acesso em: abr. 2017.

PRUS, R. Symbolic interaction and ethnographic research. New York: State University of New York, 1996. QUANDT, T.; SINGER, J. B. Convergence and cross-platform content production. In: WAHL-JORGENSEN, K.; HANITZCH, T. The handbook of journalism studies. New York: Routledge, 2009. p.130-144. 
QUÉRÉ, L. L'événement. In: BEAUD, P. Sociologie de la communication. Paris: CNET, 1997. p.401-432.

SALAVERRÍA, R. Tipologia de los cibermedios periodísticos: bases teóricas para su clasificación. Revista mediterránea de Comunicación, v.8, n.1, p.19-32, 2017.

SPYRIDOU, L. P.; VEGLIS, A. Convergence and the changing labor of journalism: towards the 'super journalist' paradigm. In: LUGMAYR, A.; DAL ZOTTO, C. Media convergence handbook - Vol. 1: Journalism, broadcasting, and social media aspects of convergence. Berlin: Springer, 2016. p.99-116.

VEGLIS, A.; DIMOULAS, C.; KALLIRIS, G. Towards intelligence cross-media publishing: media practices and technology convergence perspectives. In: LUGMAYR, A.; DAL ZOTTO, C. Media convergence handbook - Vol. 1: Journalism, broadcasting and social media aspects of convergence. Berlin: Springer, 2016. p.131-150.

\section{Telma Sueli Pinto Johnson}

É professora adjunta do Curso de Jornalismo da Universidade Federal de Juiz de Fora (UFJF). Doutora em Comunicação e Sociabilidade Contemporânea pela Universidade Federal de Minas Gerais (UFMG), com estágio pós-doutoral em 2017 pela Universidade da Beira Interior (UBI), em Portugal. Na UFJF, coordena o projeto de pesquisa "Jornalismo em interfaces móveis: mapeamentos transculturais”, homologado pelo Conselho Setorial de Pós-Graduação e Pesquisa (Res. 24/2016). Autora dos livros "Pesquisa social mediada por computador: questões, metodologia e técnicas qualitativas” e "Nos bastidores da Wikipédia Lusófona: percalços e conquistas de um projeto de escrita coletiva online”. E-mail: tjohnson@globo.com.

Recebido em: 08.12.2017

Aprovado em: 30.10.2018

Este artigo é publicado em acesso aberto (Open Access) sob a licença Creative Commons Attribution Non-Commercial (CC-BY-NC), que permite uso, distribuição e reprodução em qualquer meio, sem restrições, desde que sem fins comerciais e que o trabalho original seja corretamente citado.

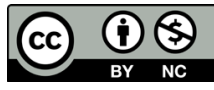

